\title{
Practicing Scrum in Institute Course
}

\author{
Hwai-Jung Hsu \\ Dept. of IECS, Feng Chia University Titansoft Pte Ltd. \\ hjhsu@mail.fcu.edu.tw eason.lin@titansof.com.sg
}

\author{
Kiki Chang \\ Titansoft Pte Ltd. \\ kiki.chang@titansoft.com.sg elton.hsiao@titansoft.com.sg
}

\begin{abstract}
Scrum is one of the most popular agile methods following Manifesto for Agile Software Development, and is a value-driven software development approach which focuses on maximizing the values of the customers. Many top software companies like Amazon.com, Apple, and Microsoft directly apply Scrum and other Agile methods for developing great software products. To raise the talents required by industry, teaching agile methods in university is necessary. However, with the limits of time, space, and experts in agile development, it can be difficult for students to learn the practices of agile methods in college. In this paper, we describe an experimental course in Feng Chia University that practices Scrum for term projects among five teams composed of 34 students. To the best of our knowledge the practices is the few attempts to practically apply all the factors described in Scrum framework such as sprint planning, daily scrum, review, retrospective meetings, product owner, and scrum master in institutional agile education. In this paper, the design and the process of the term projects based on Scrum are described, and the lessons learned from practicing Scrum in college are presented as discussion.
\end{abstract}

\section{Introduction}

Scrum [1] is one of the most popular agile methods following Manifesto for Agile Software Development [2], and is a value-driven software development approach which focuses on maximizing the values of the customers. Like all the agile methods, Scrum advocates early and frequent delivery, incremental and iterative development, and adaptive planning to face the rapid change of the real world [3]. A development team adopting Scrum continues inspecting what the customers want by frequently delivering working software and continuously adapting context variations. Scrum also stresses on transparent communication within the development team and continuous collaboration with the customers, and enables continuous improvement of the development teams for building excellent software products[4]. Many greatest software companies like Amazon.com [5], Apple [6], and Microsoft [7] directly apply Scrum and other Agile methods like Kanban [8], eXtreme Programming (XP) [9] or Lean Development [10].

Since applying agile methods becomes more and more popular around industry, to educate our students about agile becomes essential. The studies made in $[11,12,13,14]$ shown the experiences in teaching agile methods within college, and how agile methods enabling the students to deliver results more reliable and with higher quality. From 2017, we set up a graduate school course called "Agile Development" at Feng Chia University. The purpose of the course is to teach the students about the knowledge of agile methods, offers them the opportunities to experience how agile methods work, and get them understand the differences between agile methods and traditional software development process. Our course is a standard 18 weeks course with 3 hours in-class lecture each week. To get the students operating agile methods practically, after a brief lecture about a key concept within agile methods, an in-class activity like Scrum drawing game [15], Featureban [16], and flipping coin games, etc. is taken for experiencing how the concept actually works. With the assistance of the Scrum Masters from Titansoft Corp., we held a retrospective meeting at the end of the semester to help the students to inspect how and what the course brings impact to them.

With the attempt of the first-year course, we found that although the students gave many positive feedbacks of the course, there are still some issues need further improvement.

1. Although activities are arranged after lectures for concept practicing, the students still have only vague and fragmented knowledge about agile methods after all; 
2. The students are still confused in how requirements described in product backlog item can be transferred into implementation after the class;

3. The students can not understand how concepts and approaches like minimum viable product (MVP), daily scrum, and retrospective meeting impact software development without actually developing a product with them.

With the observation above and the experiences shared in $[11,12,13,14]$, we plan to get the students participating "Agile Development" in 2018 Spring to actually make their own term project using Scrum. During project development, all the meetings such as sprint planning meeting, daily scrum, review and retrospective meeting are held with facilitate from certified Scrum Master. While following the Scrum framework [1, 17] for developing their own term project, the students may also choose to implement several technical practices of agile methods such as user story mapping, pair programming, and continuous integration, etc. Thus, the students can really learn agile methods by practicing, and have deep understanding to agile methods.

To achieve the goals above, some issues need being conquered:

1. To hold all the meetings described in Scrum framework $[1,17]$ for multiple teams with only limited number of Scrum Masters, the process for sprint planning, review and retrospective meetings need being designed carefully.

2. To get the students truly understand what value means to software development, the goal of the term project for each team should be product from real requirements rather than virtual requirements especially designed for term projects.

3. In order to get the students experiencing the perception-adaptation cycle along with Scrum, the development of the term project should cross multiple sprints.

4. A common work place is suggested for grouping a development team running scrum, and the students may not share a common work place during development of the term project.

In this paper, our design of practicing Scrum for term projects for conquering the issues above is first shown. Then, the process for each team of running Scrum on term project development are described, and finally, the issues brought up during the project development are discussed. To the best of our knowledge, this course should be the first one which enable the students to run Scrum for their term project for real requirement, following the Scrum practices used in industry, and with facilitate from certified Scrum Master for the whole project.

The rest parts of the paper are organized as following: The previous experiences in educating agile methods and a brief introduction about Scrum are elaborated in section 2. The overview of the course "Agile Development" held in Feng Chia University during Spring, 2018 is described in section 3. Our design of practicing Scrum framework in term project is shown in section 4 . The process of term project development for each team and the issues brought up within the term project development are discussed in section 5. Finally, we conclude our work in section 6 .

\section{Background}

\subsection{Education of Agile Methods among Universities}

Sherell et al. conducted a graduate course entitled "Software Development Process Model." Within the course, the students are asked to develop a DVONN ${ }^{\circledR}$ game using eXtrme Programming (XP) practices for their term project. The students are separated into three roles as developers, clients, and XP researchers, and took the roles in turns along with different iterations. The results of the final questionnaire shown that the $\mathrm{XP}$ practices like pair programming and test-driven development do bring positive influences to project development [14].

Rico et al. adapted agile methods for capstone course of a master's degree in software engineering in the Fall of 2008 at the University of Maryland University College. 15 students are separated into 3 teams to build up a fully functional e-commerce websites using agile methods among 13 weeks. From the final reviews, Rico et al. indicated that the early course work about agile methods, roles, and responsibility, and appropriate coaching and mentoring can be important to such an educational project [13].

Grimheden integrated Scrum into mechatronics design education at KTH Royal Institute of Technology. To match the semester. The students executed three 8-week sprint among three semesters for their capstone project. From the process and the results of the capstone projects, Grimheden claimed that agile methods illustrate advantages in revealing core values, encouraging innovation, and project management [11].

Kropp et al. set up a new software engineering course in Zurich University of Applied Sciences 
during 2012 for teaching agile methods to graduate students. The course focuses on (1) applying engineering practices of agile methods like version control, continuous integration, and refactoring, etc.; (2) applying management practices of agile methods like planning poker and task board, etc.; and (3) teaching agile values. Kropp et al. get the students to experience agile methods by holding workshop during course hour. The students are gathered during class for sprint execution week by week. At the end of the semester, the students generally gave positive feedback to this course, but claimed that working only a couple of hours each week on the term project can not be ideal and should working an intensive week instead [12].

From the cases above, we realize that time, scattered location of the students, professional coaching and mentoring are important in educating agile practices in college. Thus, in this study, we tried our best to get the student experiencing agile development based on the real practices from the industry, and gathered the professional coaching and mentoring resources for a better learning experiences.

\subsection{Scrum}

Scrum is a development framework where cross-functional teams develop products incrementally in an iterative manner, and each iteration, called a Sprint, is a fixed time duration, usually 1 to 4 weeks. Three roles, a product owner (PO), a scrum master (SM), and the develop team (Team), are involved. Scrum emphasizes repeatedly inspecting the result product produced in a short development step, and then adapt the development processes and the goals [1].

Before any sprints start, PO, the presenter of the customers, clarifies the requirements into items formated as use cases [18] or user stories [19], and prioritizes the items into the product backlog according to the value of each item. The priority of the product backlog items may change along with the product development, and items may also be inserted or removed into/from the product backlog. The product backlog items with higher priority should be delivered earlier to realize their values, and are thus be described in more detail.

At the beginning of a sprint, a sprint planning meeting is held. In the meeting, the team first selects items from the product backlog according to the corresponding priorities. The team discusses with PO about all the details of the items selected, and makes commitment that the selected requirements would be done and delivered at the end of the sprint. With the commitment, $\mathrm{PO}$ would also not add additional items to

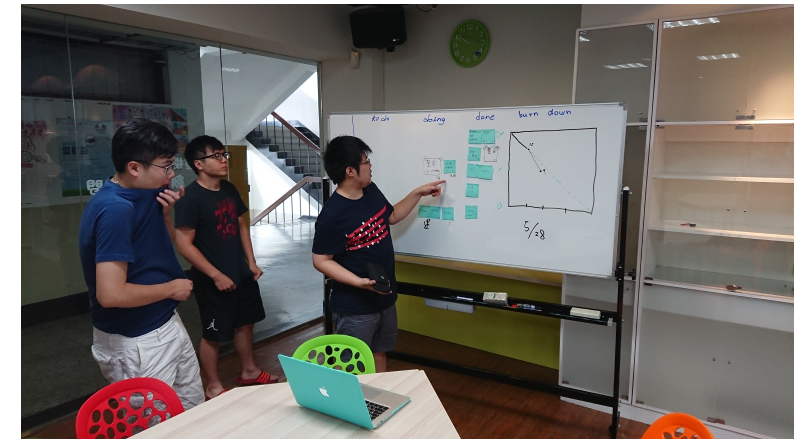

Figure 1. Daily scrum with scrum board

the team during a sprint. Scrum embraces change for the next Sprint, and the current sprint can focus on a small, clear and stable goal. After the sprint goals are settled, the team would discuss how to implement the items selected, and breaks each item into tasks according to all the implementation consideration.

The team attaches the tasks into a scrum board as Fig.1 shows, and updates the status (to-do, doing, or done, etc.) of the tasks whenever necessary. During a sprint, the team holds a standup meeting, called daily scrum, everyday. All the team members share what they have done from the last meeting, what they would like to do before the next meeting, and what is getting in their way in daily scrum. PO would also participates every daily scrum to get clear on the development progress, and answer any problems about why and what to do related to the product backlog item. The team should do their best to deliver the items they committed to accomplish, i.e. all the tasks related to the items are done and the items are ready to demonstrate in front of any of the stakeholders of the product. At the end of a sprint, a review meeting is held for demonstrating the accomplished items, called the shippable increment of the product, to PO and the stakeholders. The feedback from the stakeholders are collected, and PO would modify the product backlog according to the feedbacks and the changes of the contexts. After the review meeting, a retrospective meeting is held within the team to discuss what had happened during the sprint for clarifying what to keep in the future and what action should take to make the team better.

Besides PO and the team, Scrum Master (SM) is another essential role for applying scrum. Although with the name of "master", SM is not the manager of the team and PO, and holds no authority to the team and PO. SM is responsible for helping the team and PO follow the scrum framework and agile values. SM involves and facilitates all the meetings held within a sprint, tries his/her best to reveal all the issues within 
the team, and helps the team to perceive their situation and take actions. SM would also help PO and the team to eliminate the impediment of executing scrum outside the whole scrum team.

\section{Course Summary}

In order to teaching both theories and practices of agile methods, we offered a graduate school course entitled "Agile Development" in Spring of 2018 at Department of Information Engineering and Computer Science, Feng Chia University. The students taking the course are composed of 8 senior undergraduate students and 26 graduate students (including 3 doctoral students). The course is a standard 18-week course with 3 hours of class each week. Since not all the students are familiar to software development and none of them has experiences in Agile, during the first 8 weeks, the general concepts of agile development and the popular agile methods like Scrum, XP, Kanban, and Lean Development are introduced. In order to get the students practically experiencing the agile methods, each concept taught in class is paired with a workshop. For example, the scrum drawing game is adopted to elaborate the process of a sprint [15], Featureban is adopted for experiencing the essential issues in Kanban development [16], and flipping coin game and ball throwing game are applied for experiencing the cycle of perception-adaptation.

Besides the lectures and workshops, the students are asked to present their reports on two reading assignments, "The Scrum Guide" [17] and "Scrum and XP from the Trenches" [20]. The graduate students in Feng Chia University usually take 3 or 4 professional subjects within one semester, and do the research work for their advisor at the same time. To ask the students focusing on the term project of a class can be difficult. Therefore, after the general concepts and knowledge are introduced to the students, we start our practices of Scrum in term projects for five weeks to assure that the students can experience multiple sprints in the practices without major influences to their course and research work. The detail about the term project are described in section 4 .

\section{Practicing Scrum in Term Projects}

\subsection{Team Organization}

At the first half of the semester, the students are asked to grouped themselves into teams. Finally, we have five teams with $7,8,6,8$, and 5 team members separately. The five teams are named as Team A, B, $\mathrm{C}, \mathrm{D}$, and $\mathrm{E}$ in the following paragraphs. Among the five teams, the members within Team B, C, and E are are from the same laboratory for each team, and the members of Team A and D are mixed with students from different laboratories. Each team does not only work together for term projects, but also for each workshop and the presentation of reading assignments. During the development of term project, the Team B, C, and E use their own laboratory as the common working space. On the other hand, the lecturer reserved a classroom for the Team A and D as the common working place. These two team can freely access the classroom and keep their scrum board in the classroom during the development of the term project.

All the teams are asked to figure out their project topics from their current work. The scope of the project should be small enough that the team can implement a minimum viable product (MVP) for demonstration within 2 sprints (4 weeks), and the MVP should be able to be adopted for the future work instead of being a disposable project developed only for this course. Besides, a Product Owner (PO) is elected for each team to be responsible for making final decision of the project development. The PO of each team is responsible of maintaining the product backlog of each team and deciding whether the implementation to a product backlog item is actually fulfilled the acceptance criteria.

\subsection{Product Description}

According to the regulation setup by the lecturer, the $\mathrm{PO}$ of each team proposed a product with proper scope for their term project as following:

\section{- Team A}

The PO of Team A is an on-job doctoral student. He proposed to develop a web-site for a pharmaceuticals retailers. The requirements include merchandise demonstration, order acceptance, and on-line message communication, and is from a true project developed by the company the PO is working for. Team A planned to use PHP and MySQL to implement the web application, and the PO expects that besides the basic functions, the components developed by Team A can be applied in his future project.

\section{- Team B}

All the members of Team B are from a laboratory studying techniques of wireless sensors and Internet of Things (IoT). The PO proposed a project to build a mobile trash bin that it may move to toward to each member's seats for littering on demand. They planned to implement the mobile trash bin with a small electric powered 


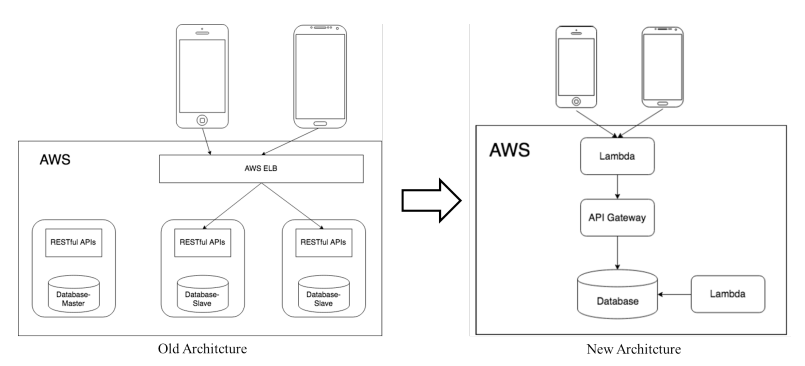

Figure 2. Comparison of the original architecture and the new architecture Team $C$ planning

wheeled robot equipped with IR sensors and an Arduino controller with WiFi modules. The WiFi module is used to accept commands and positioning, and the IR sensor is used for automatic obstacle-proof and moving direction.

\section{- Team C}

The PO of Team C developed a popular iOS App which forecasts the local weather based on open data from the Central Weather Bureau. Because the App is quite popular, the capacity of the original design is in-sufficient to handle the number of requests now. The users of the App is suffered from sudden crash during the peak moment. Since the server of the App is deployed on AWS cloud platform, the PO wish to improve the capacity of the App by refactoring the server side with lamda server and API gateway techniques. The old and the new architecture are as Fig. 2 illustrates.

\section{- Team D}

The PO of Team D proposes to build up a questionnaire generation and publication platform for data collection in future research work because the PO's study needs not only collecting the answers of the questionnaire but also how users answering the questionnaires. However, to finish the whole purpose can be too complex to the term project. In this term project, $\mathrm{PO}$ needs Team $\mathrm{D}$ to develop a very basic questionnaire platform that users can publish questionnaire with only some basic inputs like text and choices, and collect the answers from non-specific Internet users.

\section{- Team E}

The members of Team $E$ are all from a laboratory working on computer vision and robot application. Recently, they are working on developing applications on Asus Zenbo [21]. However, the SDK provided by Asus Zenbo is too simple to satisfy their requirements. Since the operating system of Asus Zenbo is actually Android, the PO of team E proposes to develop an App that users can remotely control a Zenbo using their own smart devices. Besides remote controlling, the users can also view what the Zenbo saw from its camera using real time video streaming with the App.

\subsection{The Process of the Term Project}

To get the students experience the cycle of perception-adaptation, each team would execute two 2-week sprint. Each sprint is started with Sprint Planning meeting and ended with Review and Retrospective meeting. Fig. 3 shows the schedule of the term project.

The PO of each team presented their proposal of the term project on May 1st, one week before the development of the term project launched. After the lecturer and the Scrum Masters reviewed the proposal, the PO's must hand in their product backlog based on their proposal before May 8th which is the date for the start of the first sprint. On sprint planning I held on May 8th, each team discussed and take the product backlog items they would like to accomplish within the 2-week sprint, planned how to implement the items, and made commitment to their PO that the items would be delivered at the end of the sprint. In order to reduce the time necessary for project review, we ask the PO doing just-in-time review during the sprint. In other words, whenever a task is done during the sprint, the task is demonstrated to the PO immediately instead of being demonstrated at the review meeting.

Because the students are not thoroughly devoted to the term project. We did not hold daily scrum meeting every working day. Instead, the daily scrum meetings were held two times a week for each team. Following the scrum guide [17], each daily scrum meeting should not exceed 15 minutes. The members within a team communicate to each other about their progress and obstacles. The lecturer of the course, who is also a certified Scrum Master, is responsible for facilitate each daily scrum meeting by keeping the daily scrum finished in time and guiding the team to discovering their current problems.

On 22, May, after a brief demonstration of the current product increment. The Scrum Masters from Titansoft helps all the teams doing retrospective meeting to re-examine what had happened during the first sprint. Through the retrospective meeting each team realized what they should keep and what they should improve in the next sprint. The results of retrospective meeting become the sprint goal of the next sprint, and each team 


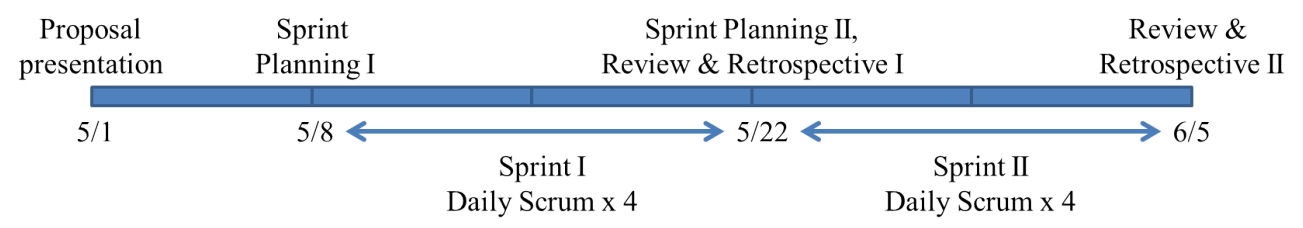

Figure 3. The schedule of the term project

\begin{tabular}{cccc} 
Team (\# members) & SP Projected & SP Done & Unit of SP \\
\hline \hline A (7) & 31 & 22 & man-day \\
\hline B (8) & 123 & 95 & man-hour \\
\hline C (6) & 81 & 76 & man-hour \\
\hline D (8) & 13 & 7 & \# tasks \\
\hline E (5) & 36 & 8 & man-hour
\end{tabular}

Table 1. The progress in Sprint I for each team

should take actions to achieve the sprint goal. After the retrospective meeting, each team started the second sprint planning meeting. With the same steps as the first sprint planning meeting, each team clarified and analyzed the tasks should be done with sprint II.

On June 5th, all the teams are gathered again for Review and Retrospective meeting. As the last meeting, a retrospective meeting which inspect the process of sprint II is held following a brief demonstration of the product increment from each team. After the sprint retrospective meeting, since June 5 th is the last date of the term project development, an additional retrospective meeting inspecting the process of the whole course is held. With this complete retrospective meeting, the students recalls what they have learned from the course.

\section{Discussion}

\subsection{The Progress for Each Team}

Table 1 and Table 2 show the statistics of the progress of each team during the two sprints. All the teams use story points (SP) to estimate and evaluate the work to be acompilshed and being done during a sprint. Each team applies different strategies for estimation. Man-hour is the most common estimation index in this practice, Team B, C, and E uses man-hour to estimate and measure their project progress. Since Team $\mathrm{E}$ is the smallest team among all the teams and the members of team $\mathrm{E}$ are worked for their advisor's project at the same time, Team E's estimation of work can be done within a sprint is much lower than the other two teams relatively. On the other hand, the members of Team A consider they have only limited time can be devoted to the project, and thus apply a rougher scale in work estimation. Team

\begin{tabular}{cccc} 
Team (\# members) & SP Projected & SP Done & Unit of SP \\
\hline \hline A (7) & 20 & 21 & man-day \\
\hline B (8) & 135 & 59 & man-hour \\
\hline C (6) & 77 & 29 & man-hour \\
\hline D (8) & 10 & 10 & \# tasks \\
\hline E (5) & 48 & 52 & man-hour
\end{tabular}

Table 2. The progress in Sprint II for each team

D does not do well in task estimation and tracks their task accomplishment merely with the number of tasks accomplished within a sprint.

From the table above, two insights can be observed. First, all the teams adjust their estimation of work according to the results of sprint I. Team A, B, and $\mathrm{C}$ have good progress in sprint I. Team A and $\mathrm{C}$ use similar SP done in sprint I for estimation of work in sprint II. Team B have a optimistic estimation of their working situation in sprint II, and raise the number of SPs in sprint II. On the other hand, Team D and E suffers serious delay of progress in sprint I. Both of the teams try their best to catch up the progress, and accomplish all the projected tasks in sprint II.

Second, the estimation of work to be done in a sprint is far from precise. Even with the experiences in work estimation in sprint I, the hidden risks can only be revealed during sprint execution. Besides team A, all the other team suffers from underestimating the difficulties of unfamiliar techniques, and meet obstacles during both the sprints. Team A seems to be avoided from the suffering because (1) the PO of team A knows the risks of the project quite well; (2) team A uses a relatively rough scale in estimation and leaves space for unexpected situation.

The details of the progress of each team during the sprints are described below.

\section{- Team A}

Since the PO of Team A is an on-job doctoral student, his experiences help Team A in estimation of how many work should be done within a sprint. Even so, Team A suffers from that less than half of the team members are familiar with the techniques of web development at the first sprint. At the first sprint, the PO, who is also a 


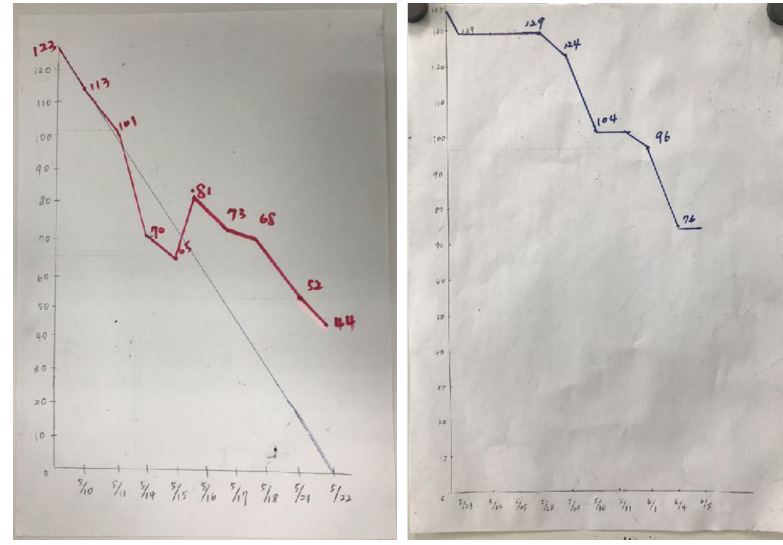

Figure 4. Team B's burndown chart left: Sprint I, right: Sprint II

developer, took responsibility in almost half of the development job. On the other hand, the members in Team A missed daily scrum in turns. All the issues are discussed in the retrospective meeting at the end of the first sprint, and are resolved at the second sprint. Team A is the only team finally accomplish all the product backlog items planned in the proposal.

\section{- Team B}

The PO and the members of Team B are the most devoted ones in the term project. As Fig. 4 shows, the rise of the burndown chart in the first sprint illustrates that there are tasks missed in the sprint planning, and thus extra works need being done. Even with the additional tasks, Team B still worked fine in the first sprint because Team $\mathrm{B}$ accomplished almost the same story points as they planned. At the same time, Team B shows great dynamic in team work. However, at the second sprint, team B met a major technique risks that their WiFi module did not work appropriately on Arduino controller. The delay in work is illustrated clearly in the burndown chart of the second sprint. All the members of Team B are devoted into solving this problem. Regrettably, the issues remain after a week hard working. Without the WiFi module, the mobile trash bin can not correctly locate itself beneath each laboratory member's seat for littering. Finally, Team B decides to use IR remote controllers for positioning. As a temporary solution, while the mobile trash bin passing by a laboratory member's seats, he/she can stop the trash bin and litter using his/her remote controller.

\section{- Team C}

Team C faced similar situation as Team B. Team $\mathrm{C}$ works terrificly at the first sprint. However, at the second sprint, they found that their customized Python library can not be properly integrated with AWS lambda service. In the middle of the second sprint, all the members of Team $\mathrm{C}$ worked together to solve this problem. Fortunately, they finally figured out a way to deploy their customized Python library onto AWS lambda service. However, this unexpected issue consumed so much time that they finished only half of the product backlog items planned in the sprint planning meeting. However, the core team member of Team $\mathrm{C}$ would continue to work on this project until all the refactoring tasks are done.

\section{- Team D}

Team D is another team which members are from various laboratory. Instead of using a physical scrum board, Team D uses Trello [22], an on-line task boards solution, to share information among the team. However, the members of Team D mis-understood the meaning of prioritizing the product backlog items. Thus, at the end of the first sprint, Team D only accomplish one item with the lowest priority that is totally against the principle of agile methods. After the first retrospective meeting, the team member devoted more into this project. At the end of the second sprint, Team D accomplished all the tasks planned for the second sprint.

\section{- Team E}

Team $\mathrm{E}$ is the team met the most troubles during term project. First, only a few members of Team E are familiar with Android programming, and it took them a couple of days to do the basic research. On the other hand, the structure of the SDK provided by Asus Zenbo is much simpler than they expected, and they found thay if they would like to achieve the original goal of the project, they must implement lots of basic components from scratch and it can not be done within two sprints. Therefore, they deliver frankly nothing at the first sprint. After discussion in the retrospective meeting, the PO of Team E decided to shrink the scope of their project to focus on develop a mechanism for remotely controlling Asus Zenbo using Smart Devices. Finally, the complete most of the tasks planned for the second sprint and gave an amazing demonstration at the final review meeting. 


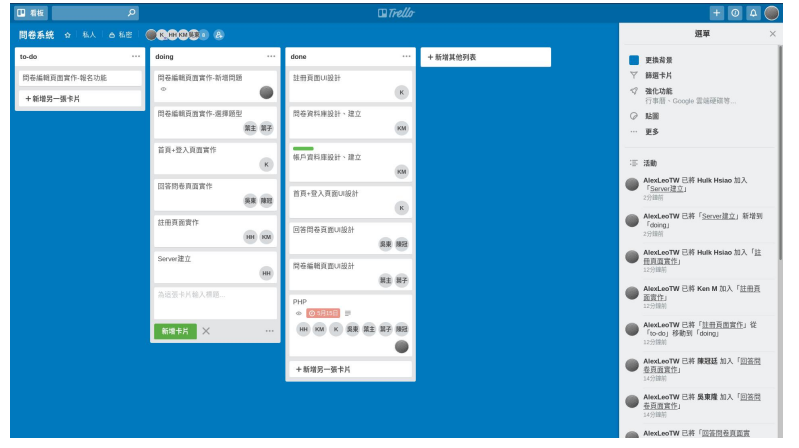

Figure 5. Team D's scrum boards on Trello

\subsection{The Lessons Learned from the Practices}

From the practices, we learned several lessons which might be helpful for practicing Scrum for term project in the future.

\section{- Regular daily scrum time}

In order to adapt the schedule of every team members, the daily scrum can be held before the beginning of everyone's class or after it. The irregularity of the time holding daily scrum influences the attendance a lot. At the second sprint, 4 out of 5 teams change their time for daily scrum meeting, and the attendance among each team becomes better.

\section{- Common working space}

The two teams using reserved classroom as their common working space have poorer dynamics in team work because they do not use the space and thus they work separately in actual. However, during the second sprint both of the team found a way to eliminate the problem that they hold additional sync-up meeting other than regular daily scrum. These additional meetings increase their time working together. However, it can still be better for a team running Scrum sharing a common working space.

\section{- The lecturer being Scrum Master}

Both Scrum Guide [17] and the Scrum primer [1] indicates that the Scrum Master must have no authority to the team member so that the team member might not consider the guiding from Scrum Master as orders. However, in our practices, the lecturer plays Scrum Master during daily scrum meeting, and the members within a team would tend to report their progress to the lecturer, the one with the power in grading their course, instead of sharing their progress and obstacles among the team.

\section{- Electronic scrum boards vs. physical ones}

Only Team D used Trello, an on-line task board tool, for presentation of the job. Trello is definitely flawed for running Scrum. As the Fig. 5 shows, it is quite easy to use Trello to simulate a scrum board, and relationships between tasks and the member doing the tasks are clear. However, Trello also has the following disadvantages while working with Scrum. (1) Trello is a task-based tool and shows no connections between tasks and the product backlog items; (2) maintaining the priority among tasks is difficult in Trello. Most matured agile team likes to apply a big physical scrum board with lots of post-it within their common working space. Trello can still be a good choice while the team is distributed; however, some extra efforts for keeping the relationships between tasks and the product backlog items and the priorities of the tasks are necessary while running Scrum with Trello.

\section{- How to scale the size of the practices up}

Since we plan to guide the scrum practice with experienced and professional Agile experts, and the scrum masters from Titansoft may supports only the sprint planning, review and retrospective meeting at the beginning and the end of a sprint. Thus, we believe the size of the class must be limited around 30 students. As a result, 34 students take the class, and we also found that this is exactly the upper bound for practicing Scrum in college courses with the resources we got right now.

Once we would like to scale up the size of the class, the scrum masters must be responsible more in coaching rather than involve the project as a scrum master. The students should first be trained how to be a scrum master, and to play the role of scrum master within the team in turns. With exchange between the roles of developers, scrum master and product owner, the students might have a better understanding of agile methods than our orginal plan.

\section{Conclusion}

In this paper, we introduce how to practice Scrum for term projects in institutional course. Our practice follows the Scrum framework that each team participating the study developing product from real requirements with facilitate from certified Scrum Master in sprint planning, daily scrum, review and retrospective meetings. Among all the meetings, the retrospective 
shows great influences in term project. All the teams change their way in doing term project after retrospective meeting, and get a better outcome in the second sprint. In the future, we will continue teach agile methods among graduate students through practicing agile methods within term projects. We will figure out the way to resolve the issues raised in this study, and realize the perception-adaptation cycle in agile education.

\section{Acknowledgment}

Special thanks to the supports from the Scrum Masters, Eason Lin, Kiki Chang, and Elton Hsiao, from Titansoft Taichung. Without them this work can not be accomplished. This research was funded in part by the Ministry of Science and Technology, Taiwan, under grant numbers 107-2221-E-035-079-.

\section{References}

[1] P. Deemer, G. Benefield, C. Larman, and B. Vodde, "The scrum primer," p. 15, 2010.

[2] M. Fowler and J. Highsmith, "The agile manifesto," Software Development, vol. 9, no. 8, pp. 28-35, 2001.

[3] K. Schwaber and M. Beedle, Agile software development with Scrum, vol. 1. Prentice Hall Upper Saddle River, 2002.

[4] M. Cohn, Succeeding with agile: software development using Scrum. Pearson Education, 2010.

[5] A. Atlas, "Scrum at amazon." https:// theagileexecutive.com/2009/07/20/

scrum-at-amazon-guest-post-by-alan-atlas/, 2009.

[6] S. Denning, "Is apple truly 'agile'?" https: //www.forbes.com/sites/stevedenning/ 2012/02/03/is-apple-truly-agile/, 2012.

[7] B. Murphy, C. Bird, T. Zimmermann, L. Williams, N. Nagappan, and A. Begel, "Have agile techniques been the silver bullet for software development at microsoft?", in Empirical Software Engineering and Measurement, 2013 ACM/IEEE International Symposium on, pp. 75-84, IEEE, 2013.

[8] D. J. Anderson, Kanban: successful evolutionary change for your technology business. Blue Hole Press, 2010.

[9] K. Beck, Extreme programming explained: embrace change. addison-wesley professional, 2000.

[10] M. Poppendieck and T. Poppendieck, Lean Software Development: An Agile Toolkit: An Agile Toolkit. Addison-Wesley, 2003.

[11] M. E. Grimheden, "Can agile methods enhance mechatronics design education?," Mechatronics, vol. 23, no. 8, pp. 967-973, 2013.

[12] M. Kropp and A. Meier, "Teaching agile software development at university level: Values, management, and craftsmanship," in Software Engineering Education and Training (CSEE\&T), 2013 IEEE 26th Conference on, pp. 179-188, IEEE, 2013.
[13] D. F. Rico and H. H. Sayani, "Use of agile methods in software engineering education," in Agile Conference, 2009. AGILE'09., pp. 174-179, IEEE, 2009.

[14] L. B. Sherrell and J. J. Robertson, "Pair programming and agile software development: experiences in a college setting," Journal of Computing Sciences in Colleges, vol. 22, no. 2, pp. 145-153, 2006.

[15] C. G. Von Wangenheim, R. Savi, and A. F. Borgatto, "Scrumiaan educational game for teaching scrum in computing courses," Journal of Systems and Software, vol. 86, no. 10, pp. 2675-2687, 2013.

[16] M. Burrows, "Featureban -
simulation to introduce kanban basics." https://www.agendashift.com/featureban, 2015.

[17] K. Schwaber and J. Sutherland, "The scrum guide," Scrum Alliance, vol. 21, 2011.

[18] K. Bittner, Use case modeling. Addison-Wesley Longman Publishing Co., Inc., 2002.

[19] J. Patton and P. Economy, User story mapping: discover the whole story, build the right product. "O'Reilly Media, Inc.”, 2014.

[20] H. Kniberg, Scrum and XP from the Trenches. Lulu. com, 2015.

[21] Asus, "Zenbo." https://zenbo.asus.com/.

[22] Trello, "Trello." https://trello.com. 